\title{
Critical Discourse Analysis of Marginalization of Local Wisdom Content in Television Documentary Program
}

\author{
$1^{\mathrm{st} *}$ Freddy Yusanto \\ Doctoral Student of dept. Com. Science \\ Universitas Padjadjaran \\ Bandung, Indonesia \\ Lecturer of dept. Comm. Science \\ Telkom University \\ Bandung, Indonesia \\ https://orcid.org/0000-0001-5039-7155
}

\author{
$2^{\text {nd }}$ Dadang Rahmat Hidayat
Dept. Communication Science \\ $2^{\text {nd }}$ Dadang Rahmat Hidayat
Dept. Communication Science \\ Universitas Padjadjaran \\ Bandung, Indonesia \\ dadang.rahmat@unpad.ac.id

\author{
$4^{\text {th }}$ Yasraf Amir Piliang \\ Dept. Art \& Design \\ Institut Teknologi Bandung \\ Bandung, Indonesia \\ yappiliang@gmail.com
}

$3^{\text {rd }}$ Rahmat Edi Irawan

Dept. Communication Science

Universitas Padjajaran

Bandung, Indonesia

reirawan@yahoo.co.id

\begin{abstract}
This study wants to examine the background of the local wisdom content marginalization in Indonesia Bagus television documentary program. This study uses a critical discourse analysis approach from Fairclough which explains how the marginalization of local wisdom content is carried out, how the production team does it, whether any power plays a role and how the audience interprets the concept change. The analysis of this study considers on NET's financial condition, CEO changes that lead to resign offer to employees, which then creates a discomfort atmosphere for NET employees. This is what underlies the marginalization of the content that is deemed not to produce a high rating and share. One of the programs that were affected by the conditions of NET are documentaries Indonesia Bagus. The Indonesia Bagus program changed the concept from an observational documentary program that was loaded with local wisdom content into an expository documentary program with a more dominant element of entertainment. A concept change that has to 'strip away' the function of information, education, and social control over local wisdom content as a cultural identity. The expectations of this concept change, of course, to raise its rating and share. But in fact, the concept change produces a decline in ratings and share in Indonesia Bagus program. This research is expected to be a reference in television documentary studies to see how a context plays a role in the production process of documentary television programs and how local wisdom content can be used as informative, educational and entertaining television program content; to provide a positive understanding for the younger generation in the process of strengthening the identity of Indonesia.
\end{abstract}

Keywords - local wisdom, marginalization, documentary program television

\section{INTRODUCTION}

Television which initially acted to spread information, provide supervision, and entertainment, has now become a media forming the reality of the audience as well as a seller of popular culture [1]. Popular culture is always associated with industrialization in the capitalist system which leads to consumerism [2]. There must be an awareness of media stakeholders to be more active in presenting local wisdom as television program content. The wealth of local wisdom in Indonesia can be used as an alternative content to be popularized by the media. Indonesia Bagus program, with an observational documentary style, since 2015 has featured an informative and educational content about the local wisdom of the Indonesian nation. This program has also received several awards; among them the best documentary program KPI Award three times. But then in mid-2018, to raise the rating and share, this program changes into a documentarystyle expository. The expository style features a light storyline, displays beautiful or handsome hosts, prioritizes the exploration of popular content such as culinary, tourist attractions and so on. This is where the authors see that there has been a marginalization of local wisdom content. An observational style that displays local wisdom in-depth, providing information about lifestyle, philosophy, and meaning of existing local culture; they just disappear. One of the things that need to be considered in a documentary is the existence of a conjunctive relationship between each scene. Subsequent scenes can show the next or previous event, by presenting contrasting content, similar content, and so on [3]. The flow of the story is needed by the audience to get an understanding of the entire message delivered. Ironically, the concept change that aimed at raising ratings and shares was not successful, instead, it declined. This, according to the author, is interesting to analyze.

Titi Nur Vidyarini in the journal 'Popular Culture in Television Program Packaging' states that popular culture emerged as a counter-culture of established local wisdom [1]. Local wisdom that has moral values and rules for the community in the running of social interaction and resulting from a long and complex history, later replaced by a popular culture that offers ease and pleasure that resulted in information and education which is delivered has superficiality information. Popular culture is always associated with industrialization in the capitalist system which 
leads to consumerism. Our siege in popular culture, without us knowing, will bring a popular way of thinking too. By experiencing the instant culture, not respecting the process, proud of the appearance, overriding the meaning and busy with love become something normal. Popular ways of thinking make us prioritize pleasure over knowledge. Popular culture is built on popular imagination deliberately built by minorities against the majority. Popular ways of thinking finally create an ideology of popularism and popular imagination that finally leads us to think instantly, profane and superficial [2].

Titi Nur Vidyarini stated that popular culture emerged as a counter-culture of established local wisdom, however, if we study the case of the Good Indonesia program, the popular style that is displayed as a counter culture of local wisdom content does not necessarily make ratings and shares rise. This means that instant culture prioritizes one's physical appearance as a host, provides content about pleasure (tourism, culinary), but overrides knowledge about local wisdom and, it turns out, does not promise business profits. The author sees this analysis will provide another perspective related to how to treat local wisdom content so that it can be enjoyed by the public. The author sees local wisdom content has the same opportunity to get space, like popular content that has appeared on Indonesian television programs.

The researcher limits this research to how the process of local wisdom marginalization content occurs on documentary television program Indonesia Bagus. The author will analyze this problem by using Fairclough's model critical discourse analysis which is called the social change model. On television documentary program Indonesia Bagus, researchers will see how the text is produced using observational and expository styles, so we can find out the background of how the text was made. The researcher will also conduct a broader analysis of the discourse so that the researcher can conclude the context underlying the change. This analysis will explore the facts about the background of the marginalization of local wisdom content, how the production team does it, whether there is any role in power and how the audience interprets the concept change. The author wants to see what happens behind the marginalization of local wisdom content in the Indonesia Bagus program.

\section{RESEARCH METHOD}

This analysis uses a critical perspective, referring to the analysis of Fairclough discourse which is often referred to as a model of social change. Discourse is a form of action that implies a reciprocal relationship between discourse and social structure. Fairclough divides discourse into three dimensions: text, discourse practice, and sociocultural practice. To understand a discourse (manuscripts/text), we must focus on the context. For this reason, a search for the context of production, consumption and socio-cultural aspects influences the making of discourse (manuscripts/texts) [4][6].

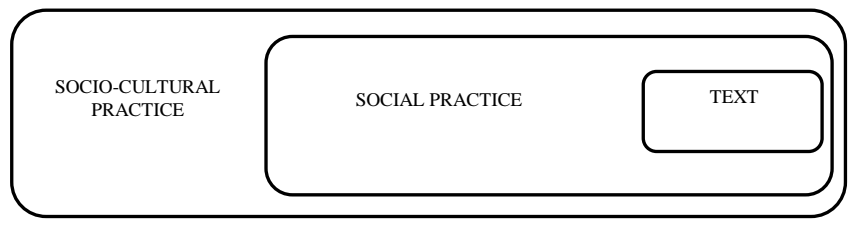

Fig. 1. Fairclough Analysis Model
Primary research data will be taken from interviews with program producers Indonesia Bagus NET, while secondary data from research program documentation Indonesia Bagus Episode "Nias Island" (representing the concept of observational documentaries) and the episode "Extreme Culinary in Yogyakarta" (representing the concept of documentary expository). To get a response from the audience for its concept change, the writer conducted an FGD with several Indonesia Bagus program audiences. This analysis focuses on the production team interaction process, looking at how the element of power plays a role in this change process, and how the audience responds.

\section{CRITICAL REVIEW}

Local wisdom as a way of life, science, socio-cultural system and various life strategies that are manifested in the activities of local communities [7] can be represented strongly and deeply in an observational documentary style. This is because cultural information and socio-cultural conditions are conveyed directly by cultural actors (subjects). Interaction between elements built in this documentary program can build an understanding of local wisdom, build a passion to maintain, improve and develop elements of need by taking into account the environment and human resources. Providing an understanding of local wisdom is important because local wisdom is a reference for the community in carrying out social interactions in their daily lives.

The concept of the Indonesia Bagus documentary program with this observational style has led him to win the KPI Award as the best documentary program in 2014, 2015 and 2017.

TABLE I. ACHIEVEMENT OF INDONESIA BAGUS DOCUMENTARY PROGRAM

\begin{tabular}{|c|l|c|}
\hline Awards & \multicolumn{1}{|c|}{ Name of Program } & Note \\
\hline KPI 2014 & Indonesia Bagus - Nias & $1^{\text {st }}$ winner \\
\hline KPI 2015 & $\begin{array}{l}\text { Indonesia Bagus - The pride of Tarak tale } \\
\text { Fak Fak village, Papua }\end{array}$ & $1^{\text {st }}$ winner \\
\hline KPI 2016 & $\begin{array}{l}\text { Those who are tough - Making hope } \\
\text { Reaching the dreams (Global TV) }\end{array}$ & Nominated \\
\hline KPI 2017 & Indonesia Bagus - Mappadendang & $1^{\text {st }}$ winner \\
\hline KPI 2018 & Lentera Indonesia Net TV & Nominated \\
\hline
\end{tabular}

But apparently, the award is not corresponding with the rating and share gained by Indonesia Bagus documentary program. In TVR performance, it can be seen that from 2018 to mid-2019, on average only get 0.2 points. As for the trend for audience share, from February 2019 there was a decline in points until the program was finally stopped in mid-2019 (See Table 3). 


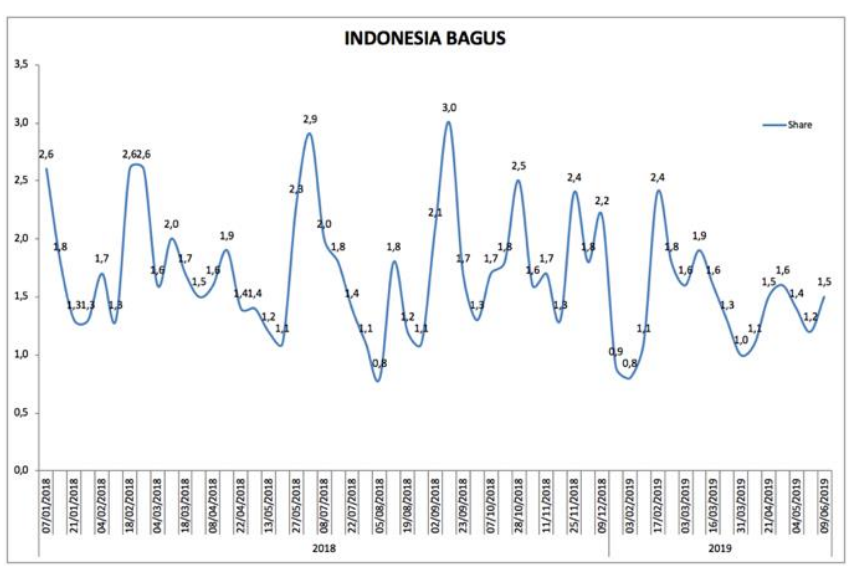

Fig. 2. Performance chart Indonesia Bagus documentary program

The data is different seen from the viewers of the Indonesia Bagus documentary program on YouTube since January 2017 - March 2018 (observational style), all the Indonesia Bagus programs on Youtube have viewers above 10,000. While starting in April 2018 - December 2018, only 5 episodes get viewers above 10,000. From these data viewers, we can analyze that there is a significant reduction between observational style documentary programs and expository styles.

TABLE II. RATING \& SHARE AC NIELSON VS VIEWERS YOUTUBE

\begin{tabular}{|l|l|l|}
\hline & \multicolumn{1}{|c|}{ AC Nielson } & \multicolumn{1}{c|}{ Viewers Youtube } \\
\hline Observational & TVR $0,2-$ Share & $100 \%$ above 10K Viewers \\
Style & 1.8 & \\
\hline Expository & TVR $0,1-$ Share & $5 \%$ above 10K Viewers \\
Style & 0.6 & \\
\hline
\end{tabular}

There is a difference in data between rating \& share based on television media and viewers based on YouTube media. This data represents 2 audience characters, namely nonmillennial generation viewers (rating \& share) and millennial generation (YouTube viewers). Television media audience (non-millennial generation) from the beginning of the Indonesia Bagus program emerged, not very popular with the audience (TVR $0.2 \&$ share 1.8). After transforming the style to documentary expository, the rating \& share did not experience any improvement, decreasing instead (TVR 0.1 \& share 0.6). From the data on YouTube, it can be seen when presented in an observational documentary style, this program is in demand by an audience with the acquisition of viewers above 10 thousand, after experiencing a change in style to expository, then viewers above 10 thousand are only as much as $5 \%$. This shows that the millennial audience prefers the observational style to the expository style.

The author sees that problems appeared when changes in documentary-style occur. This can be seen in the following table.
TABLE III. PROBLEMS THAT ARISE ARE RELATED TO THE CHANGE IN THE CONCEPT OF THE INDONESIA BAGUS DOCUMENTARY PROGRAM

\begin{tabular}{|l|l|l|}
\hline No. & \multicolumn{1}{|c|}{ Problems } & \multicolumn{1}{c|}{ Justification } \\
\hline 1 & $\begin{array}{l}\text { The loss of depth on } \\
\text { local wisdom events } \\
\text { (cultural, socio- } \\
\text { cultural conditions) }\end{array}$ & $\begin{array}{l}\text { There is no data confirmation for } \\
\text { cultural actors/people who are } \\
\text { competent with a local wisdom } \\
\text { * Style of delivery and speaking style } \\
\text { that does not blend with the regional } \\
\text { atmosphere } \\
* \text { The gap between the host character } \\
\text { and the local community }\end{array}$ \\
$\begin{array}{l}\text { The emergence of an } \\
\text { opinion or cognition } \\
\text { of local wisdom } \\
\text { events to the } \\
\text { information } \\
\text { submitted which had } \\
\text { previously been } \\
\text { through the process } \\
\text { of sorting } \\
\text { information. }\end{array}$ & $\begin{array}{l}\text { Choice of host sentences in the speech } \\
\text { that do not represent the owner / cultural } \\
\text { actor } \\
\text { Explanation of information conveyed } \\
\text { is not exhaustive, due to limited } \\
\text { references from the production team on } \\
\text { the local wisdom of an area }\end{array}$ \\
$\begin{array}{l}\text { The interaction } \\
\text { between } \\
\text { elements semiotic } \\
\text { mode) built is not } \\
\text { harmonious due to } \\
\text { the appearance of } \\
\text { several gaps in the } \\
\text { sign element. }\end{array}$ & $\begin{array}{l}* \text { Host character, gesture, wardrobe, } \\
\text { property with Jakarta centric style create } \\
\text { a gap between the host and the local } \\
\text { community } \\
\text { Jakarta-centric speaking style makes } \\
\text { the host have a distance from the local } \\
\text { community }\end{array}$ \\
\hline 3
\end{tabular}

According to the interview with the producer of the Indonesia Bagus program, Raden Harris Fadhilla said that Indonesia Bagus program was in terms of content and artistic has been good so far, it was proven that this program had received several awards from various television program awards. However, Nielsen's survey results were not as expected. Until early 2018 Indonesia Bagus has not been able to attract advertisements as expected. Ad producers still haven't been interested in this program. Changes to creative concepts are then made and finally, concepts are placing the host chosen by the producer team. The consideration for this case is that the chosen host has a more attractive and up-todate appearance. It is undeniable, Indonesian people prefer watching a cool and modern talent, even though it reduces the regional character representation in the documentary program. Placing a host from Jakarta is technically very helpful for the production team in taking pictures. The host is adept at composing sentences and can show very relaxed gestures, resulting in an entertaining program display. However, it is recognized by Harris that the overall appearance with a new concept (expository), produces a different feel when compared to the observational style. The story that was built became less profound and was impressed that the host as the master of ceremonies did not understand the local wisdom of the local area. Awkward gestures when having to interact with the surrounding community are very pronounced and in the appearance of the program, it creates boundaries between the host and the local community. Wardrobe, makeup, and property that is used seem to strengthen the gap between the two. One thing that looks significantly different between these 
two concepts is the artistic side. When it uses the observational style, the writer sees the production team very attentive to its artistic details. The author observes the neat editing techniques, featuring a coherent storyline, creating an impression that's full of entertainment (visually), information and education. Whereas in the expository style, the writer did not find any of these things. The motivation of each shot is not well dramatized. Beauty Shot is a mainstay visually in a documentary program, received less attention.

Finding the facts that show that the Indonesia Bagus program rating \& share is getting worse, it is really beyond the expectations of the production team. Producer expects, by changing the style from observational to expository and placing a Jakara centric-style host, this can increase the rating and share of the Indonesia Bagus program. The author then tries to search related to NET news from the beginning of 2018 until the middle of 2019. On August 29, 2018, NET plans to sell its shares on the Indonesia Stock Exchange (IDX) by $25 \%$ of shares issued and paid to the public. $19.32 \%$ of the released NET shares are convertible to mandatory convertible bonds and the remainder are shares released to the public through an Initial public offering (IPO) scheme. Issuance of mandatory convertible bonds is estimated to get funds in the amount of Rp 800 billion, while from the IPO it is targeted to get funds of Rp 200 billion, so the target of fresh funds obtained by NET is Rp 1 trillion. NET filings with using bookkeeping in March 2018 and plays on the Stock Exchange on August 29, 2018. As of May 24, 2019, NET is still recorded in the data pipeline of new issuers will conduct an IPO in 2019, but the list of pipeline BEI per July 8th, 2019 the name Net Visi Media no longer [8][9].

Since April 5, 2019, there has been a change of CEO at NET from Wishnutama to Deddy Sudarijanto. Then in August 2019, NET Chief Operating Officer Mediatama Azuan Syahril stated that NET made an offer to its employees to resign by giving compensation as one of the company's efficiency efforts. The very tight competition in the television industry now requires a special strategy so that the company can survive [10]. During June - August, NET made some significant changes to the program. Changes in the composition of the NET program are seen in the News division program, which is only aired for 1 hour out of 6 hours. The Production Division program is given additional airtime to make programs more mainstream, one of which is Santai Siang (Sayang) program. This program is similar to Ceriwis which was once popular on Trans 7 and aired for 2 hours. But then experienced a trimming duration to 1 hour. Some cartoon programs also began airing a lot, this was done to reduce production costs. NET programs start to look identical to other television station programs, variety programs with longduration programs such as Sayang programs and programs with mystical themes (Merinding) now can be watched by NET audiences. This happened along with changes to the leadership structure on NET.

Based on the data the authors describe, in the mid-2018 to mid-2019 period, the internal atmosphere at NET was not in a good condition, as evidenced by the plan to sell shares, change the CEO and offer to resign for his employees by giving compensation as wrong one company efficiency effort. This condition causes the Indonesia Bagus program to be able to get out of the low rating \& share pressure so that the producers finally change the concept in order to raise their rating \& share. Until mid-2019, there was no improvement in terms of rating \& share, finally, the Indonesia Bagus program stopped serving. At that time, there was a change of CEO at NET. According to the authors, this condition is related to the change in orientation from the previous CEO. The new CEO focused on efforts to increase the number of viewers and, at the same time, also made efficient production costs by reducing the portion of the News department's very significant broadcast hours, giving additional production hours to the production department team to produce mainstream programs, airing several programs re-run and provide airtime for approximately 7 hours per day for animated shows. This transition atmosphere affects the performance of NET employees. This can be seen from the decline in artistic quality and the storyline displayed in the Indonesia Bagus program in its new concept. In the Group Discussion Forum (FGD) that the writer conducted with 15 informants, they stated that there were differences between the two concepts of the Indonesia Bagus documentary. The average informant stated that the expository style was the same as other programs such as Jejak Adventurer, Portrait, Explore Indonesia. This program visually becomes less attractive. The appearance of a combination of framing landscape with details as shown in the observational style is less pronounced in an expository style. Besides, the depth of exploration related to the information being discussed is not well explored, so the information conveyed to the audience is the only surface. This makes the informants less interested in participating in the Indonesia Bagus program with an expository style.

\section{CONCLUSION}

The concept change in Indonesia Bagus documentary program can be used as a sample case that changing the concept by merely promoting entertainment and reducing the depth of information and education, apparently does not necessarily result in higher ratings and shares. The author analyzes from the discourse of social and socio-cultural practices, that the situation and condition of NET becomes a strong reason for the concept change made on Indonesia Bagus program. It turns out that conditions and situations in the work environment are closely related to the performance of the production team. NET conditions that are experiencing financial problems as well as CEO changes and resign offers to employees create another uncomfortable atmosphere for NET employees so that it impacts on the performance of the production team. Local wisdom content should be encouraged as content that can offer alternatives to popular culture content. It takes courage for television stakeholders to continue to show programs that raise local wisdom. This research shows that programs with local wisdom content have the opportunity to become a program that is suitable for public interest.

\section{REFERENCES}

[1] G. Eason, B. Noble, and I. N. Sneddon, "On certain integrals of Lipschitz-Hankel type involving products of Bessel functions," Phil. Trans. Roy. Soc. London, vol. A247, pp. 529-551, April 1955. (references)

[2] J. Clerk Maxwell, A Treatise on Electricity and Magnetism, 3rd ed., vol. 2. Oxford: Clarendon, 1892, pp.68-73

[3] I. S. Jacobs and C. P. Bean, "Fine particles, thin films and exchange anisotropy," in Magnetism, vol. III, G. T. Rado and H. Suhl, Eds. New York: Academic, 1963, pp. 271-350.

[4] K. Elissa, "Title of paper if known," unpublished. 
[5] R. Nicole, "Title of paper with only first word capitalized," J. Name Stand. Abbrev., in press.

[6] Y. Yorozu, M. Hirano, K. Oka, and Y. Tagawa, "Electron spectroscopy studies on magneto-optical media and plastic substrate interface," IEEE
Transl. J. Magn. Japan, vol. 2, pp. 740-741, August 1987 [Digests 9th Annual Conf. Magnetics Japan, p. 301, 1982].

[7] M. Young, The Technical Writer's Handbook. Mill Valley, CA: University Science, 1989 